\title{
O desenvolvimento da habilidade da criança para narrar experiências pessoais: uma revisão da literatura
}

\author{
Lídia Macedo \\ Tania Mara Sperb \\ Universidade Federal do Rio Grande do Sul
}

\begin{abstract}
Resumo
A participação dos pais no desenvolvimento de habilidades cognitivas e comunicacionais dos filhos vem sendo analisada, nos últimos quinze anos, especialmente a partir de uma perspectiva sociointeracionista. Pesquisas recentes indicam que as crianças aprendem a falar sobre suas memórias de eventos passados de uma maneira organizada, num contexto colaborativo de engajamento com seus pais. Alguns autores propõem que o desenvolvimento das formas narrativas possibilita à criança criar um significado para as experiências vividas. Este artigo tem como objetivo revisar a literatura sobre o desenvolvimento da habilidade da criança para narrar suas experiências pessoais, bem como sobre o papel do suporte verbal oferecido pela mãe durante esse desenvolvimento.
\end{abstract}

Palavras chave: interação mãe-criança; linguagem; habilidade narrativa

\begin{abstract}
The development of child's ability to tell personal experiences: a literature review. Parents' participation in the development of their children cognitive and communicative abilities has been analyzed in the last fifteen years especially from a social interactionist perspective. Recent studies indicate that children learn to narrate about their memories of past events in an organized manner, in collaboration with their parents. A number of authors suggest that the development of narrative forms allow the child to create meaning for their living experiences. The aim of this article is to revise the literature on the development of children's ability to narrate their personal experiences as well as on the role of the verbal support offered by the mother in the course of this development.
\end{abstract}

Keywords: mother-child interaction; language; narrative ability

$\mathrm{H}$ á muitas histórias a serem contadas, mas é preciso primeiro aprender a contá-las. Fivush e Haden (1997) consideram que as histórias são bem mais do que um meio conveniente de comunicar nossas experiências aos outros. Elas se constituem, antes de tudo, num meio para compreender a vida e a nós mesmos.

Bruner (1987) acredita que as maneiras de contar o que se viveu e os meios de conceitualizar que as acompanham tornamse tão habituais que constituem formas de estruturação da experiência. Essas formas narrativas, segundo o autor, organizam e provêem o contexto adequado para o relato de vivências pessoais. Elas determinam quais aspectos da experiência vivida serão expressos, e como, tornando a atribuição de significado possível. A vida em sociedade leva as pessoas a adquirirem suposições coletivas com respeito a regras a serem seguidas nas narrativas, e por essa razão, as histórias que aderem a essas regras são mais facilmente reconhecíveis e contáveis (Bruner, 1991). Sabe-se, no entanto, pouco sobre como se desenvolve esse processo de aprender a narrar coerentemente as próprias experiências no contexto familiar.

Diversas pesquisas (Fivush, 1991; Fivush \& Haden, 1997; Low \& Durkin, 2001) mostram que as crianças aprendem a falar sobre suas memórias de eventos passados de uma maneira organizada, num contexto colaborativo de engajamento com seus pais. Segundo Fivush e Haden (1997), o desenvolvimento das formas narrativas pode influenciar a maneira como a criança pequena entende e representa suas experiências no mundo real, e ainda, que por meio do ato de narrar, a criança cria e confere significado à sua própria vida.

Este artigo revisa a literatura a respeito de como a criança aprende a narrar suas experiências pessoais, uma habilidade cuja aprendizagem ocorre durante os anos pré-escolares. Foram revisadas as pesquisas produzidas na última década, mas também foram incluídos alguns trabalhos considerados clássicos na literatura sobre o tema. Para tal, foi feita uma busca computadorizada no Portal SciELO (www.scielo.br), no indexador eletrônico Google e no PsychINFO (http://psycinfo. apa.org/psycarticles/direct/), com os descritores narrativa, 
criança, experiências pessoais. Finalmente, foi feita uma busca na lista de periódicos divulgada pela CAPES (http://servicos. capes.gov.br/webqualis/) em que constam, por área, as revistas Qualis $A, B$ e $C$, além de uma busca manual em periódicos da área da psicologia, por meio do cruzamento das referências mais citadas sobre narrativas de experiências pessoais de crianças.

Neste artigo, introduzimos a perspectiva sociointeracionista para o estudo do desenvolvimento da criança, o referencial teórico que o embasa, para, em seguida, discutirmos o papel da interação social na aprendizagem da narrativa. Por fim, analisamos o desenvolvimento da habilidade da criança para narrar uma experiência vivida.

\section{Uma perspectiva sociointeracionista para estudar o desenvolvimento da criança}

Para explicar o desenvolvimento na perspectiva vygotskiana, é necessário estudar os processos que ocorrem entre o organismo em desenvolvimento e seu ambiente (Valsiner \& Benigni, 1986). Para esses autores, quando a premissa da interdependência entre o fenômeno e seu ambiente é aplicada à pesquisa empírica, o processo de interação fenômeno-contexto se torna a unidade de análise. Enfatiza-se, assim, a necessidade de contextualizar o fenômeno psicológico, o que torna possível compreender como o fenômeno se relaciona com os contextos em que ocorre. Para compreender o contexto da criança em desenvolvimento, segundo Valsiner e Benigni (1986), é preciso examinar o papel dos significados da cultura.

Desde seu início, o desenvolvimento da criança ocorre em um contexto de significados definidos pela cultura que, ao oferecerem esquemas para a compreensão das metas e métodos de educação aos pais, conduzem o desenvolvimento da criança. Valsiner e Benigni (1986) explicam que, quando a criança desenvolve uma dada atividade sociocultural, inicia-se uma seqüência natural de trocas com o ambiente, que lhe fornecerá um feedback de sua ação. Este feedback já modificado será usado por ela, num próximo momento, para agir sobre o ambiente. Assim, pressupõe-se também que a criança constrói e reconstrói ativamente seu ambiente, como também faz uso do que construiu mais adiante em seu desenvolvimento.

Decorre dessa perspectiva um interesse em compreender como emergem fenômenos qualitativamente novos no agir ou pensar da criança. Nesse artigo, o fenômeno a ser enfocado refere-se à como a criança desenvolve a habilidade para narrar suas experiências pessoais e a utilização que ela faz do suporte verbal oferecido por sua mãe.

Para Vygotsky (1930/1989), os mais experientes (experts) da cultura ajudam os novatos a se tornarem experientes quando constroem pontes entre o nível de desenvolvimento atual e o nível imediato futuro. Rogoff (1990) amplia essa idéia, teorizando sobre o processo de apropriação da cultura. Para a autora, os recursos e indicações oferecidos pelos mais experientes e as práticas culturais para definir e resolver problemas conduzem a criança a transições qualitativas e quantitativas no seu modo de pensar e agir, as quais possibilitam lidar de forma mais efetiva com os problemas diários. As atividades socioculturais constituem settings ideais de apropriação da cultura. Nessas ocasiões, as informações e habilidades não são apenas transmitidas, mas transformadas no processo de apropriação. A atividade social guia o caminho a ser tomado, mas não o determina, pois os indivíduos escolhem em quais aspectos da atividade prestar atenção, quais ignorar, e ainda transformam o que foi disponibilizado, fazendo adaptações para uma utilização futura.

Para Rogoff (1990), essas atividades constituem settings culturalmente organizados de comunicação adulto-criança, como quando adultos integram as crianças em suas próprias atividades (tolerando a intrusão ativa da criança), ou quando adultos envolvidos em suas próprias atividades permitem que a criança "veja e ouça" (desenvolvendo sua compreensão, enquanto aprende observando). A condução ativa dos outros sociais é complementada pela construção feita pela própria criança de seu desenvolvimento.

O processo de desenvolvimento envolve uma constante construção de pontes entre o presente e o futuro, isto é, entre o conhecido e o novo. Para Rogoff (1990), existem dois níveis de construção de pontes ou de apoio social. O primeiro é o apoio dos outros sociais às ações da criança no contexto de uma tarefa, o que a ajuda naqueles aspectos da ação nos quais ela é ainda incapaz. Há uma organização hierárquica nas tarefas de resolução de problemas e por essa razão a estruturação por parte do adulto pode estar em diferentes níveis. Além disso, a estruturação das estratégias de resolução de problemas conduz ao desenvolvimento da habilidade para transcender a demanda de uma tarefa particular. Isso leva ao segundo nível de construção de pontes e apoio social: o uso do diálogo. Para a autora, o apoio verbal da fala do adulto num determinado setting de resolução de problema guia a compreensão geral da criança com uma narrativa que utiliza conceitos da cultura. O setting examinado neste artigo é a narrativa de experiências pessoais da criança em seu ambiente familiar o que, se não faz parte da vida diária, ao menos constitui uma rotina na comunicação entre mãe e filho. Além disso, é uma atividade na qual se pode apreciar claramente o apoio verbal da fala do adulto, assim como o uso que a criança poderá fazer dele.

Em suas considerações sobre a teorização de Rogoff, Valsiner (1991) destaca o problema das reduções. Segundo o autor, para Rogoff toda a estrutura psicológica intrapessoal restringe-se a ações externas dentro de contextos apoiados socialmente. Por outro lado, também reduz a estrutura do mundo social externo a settings de resolução de problemas. Além disso, os processos mentais se tornam subservientes à ação, e o agir eficientemente seria o próprio propósito do pensar. Valsiner considera que não fica claro como emergem dentro da mente as funções psicológicas novas vindas desse fluxo de intersubjetividade. Segundo ele, esses problemas decorrem da noção de fusão entre a pessoa e a cultura, defendida por Rogoff.

Para resolver essa questão, Valsiner (1991) propõe a estratégia da separação inclusiva, isto é, pessoa e cultura são reconhecidas como fenômenos separados, porém com uma interdependência obrigatória entre eles. Segundo Costa e Lyra (2002), a separação inclusiva resgata a singularidade do sujeito, o seu lugar no mundo, em um processo incontestável de imersão na cultura e nas relações sociais. Para Valsiner (1991), essa estratégia permite a análise explícita de ambas as formas de 
organização, a interna e a externa, e da transformação delas, com a ajuda da atividade sociocultural. Costa e Lyra acrescentam ainda que é a capacidade semiótica do sujeito que o faz emergir da cultura como um ser que pensa sobre ela, um ser que utiliza os instrumentos socioculturais que simultaneamente constituem sua autonomia e permitem sua diferenciação, enquanto o mantém inseparável da cultura.

Para Valsiner (1991), a noção de apropriação de Rogoff (1990) descreve o processo de internalização/externalização que é responsável pela construção individual das culturas pessoais. Dessa forma, a pessoa detém o papel central e faz a constante correspondência entre o mundo real e o seu próprio mundo. Para o autor, a pessoa cria construções híbridas a partir da internalização de diferentes vozes que são transformadas internamente, de modo que serão externalizadas novas mensagens, já misturadas com as suas próprias intenções.

É possível, a partir dessas informações, compreender a atividade sociocultural de conversar sobre experiências passadas como um setting de apropriação da cultura, adotando-se uma estratégia de separação inclusiva. Um setting em que a criança internaliza informações e habilidades narrativas durante as narrativas de sua mãe e durante as suas tentativas de narrar acompanhadas das intervenções de apoio materno, e externaliza em suas narrativas posteriores o resultado das transformações que efetuou nessa troca.

\section{Aprender a narrar na interação com o outro}

Na teorização de Vygotsky (1930/1989), a criança, ao aprender as habilidades necessárias para realizar uma dada tarefa cognitiva em colaboração com o adulto, também aprende os tipos de tarefas cognitivas valorizados culturalmente, aquelas habilidades que são necessárias para alguém tornar-se um membro da cultura. Entre essas, segundo Bruner (1990/1997b), está a aquisição da habilidade narrativa que confere estabilidade à vida social da criança. Além disso, essa habilidade cognitiva irá ancorar a futura produção escrita de histórias (Silva \& Spinillo, 2000). E ainda, como argumenta Matta (2004), a habilidade narrativa, juntamente com a organização categorial, constituem formas de ordenar a memória e o conhecimento. Estas formas serão fundamentais para que o conhecimento prático possa evoluir para um sistema abstrato, teórico e formal.

Os adultos próximos da criança têm um papel específico a desempenhar no que concerne ao desenvolvimento de sua habilidade para narrar. Brockmeier e Harré (2003) argumentam que as crianças desde cedo são ensinadas a contar histórias, uma vez que, se ao contá-las, não utilizarem devidamente as convenções, os ouvintes reclamam, param de ouvir, zombam, corrigem o narrador, etc. Já por parte da criança, segundo Dunn (1988), existe um entusiasmo natural por narrativas, que evidencia uma prontidão para explorar e compreender o mundo social, o que deve ser encorajado e desfrutado pelos adultos de seu ambiente imediato.

Contudo, Becker (2005) adverte que embora os processos interacionais contribuam com uma grande parte do desenvolvimento narrativo, é preciso diferenciar os gêneros narrativos. A autora ressalta que o modelo de como contar uma experiência é o único que é essencialmente extraído de experiências conversacionais com suporte de um adulto. Os outros gêneros, como as histórias de fantasia, dependem mais de um tipo de conhecimento específico que a criança obtém por meio de experiências prévias com outros textos narrativos.

$\mathrm{Na}$ interação verbal adulto-criança, segundo Michaels (2002), o adulto precisa captar o tópico oferecido pela criança e ajudá-la a prosseguir por meio de afirmações, questões e respostas. Para que esse suporte seja eficiente, o adulto deve antecipar a direção em que o tema vai se desenvolver. Desse modo, a criança vai construir a narrativa tomando como base as perguntas do adulto. Como lembra Perroni (1992), essas perguntas exigem da criança o preenchimento de elementos dentro de uma estrutura típica de discurso narrativo.

Entretanto, o papel do adulto nas interações narrativas modifica-se durante o desenvolvimento da criança. Miranda (2000), em uma pesquisa brasileira com crianças de três a cinco anos e professoras, pôde constatar três formas diferentes de assistência por parte do adulto. Quando a criança ainda mostra pouca elaboração, o adulto funciona como modelo, questiona mais, conduz o processo de narração e assume co-autoria. Com a crescente autonomia da criança, o adulto passa a ser um ouvinte participante que escuta atentamente, acompanha a narração e faz intervenções para ampliar a narrativa. E por fim, o adulto é o interlocutor que solicita maior elaboração e produções mais complexas. Em um estudo longitudinal que acompanhou duas crianças brasileiras dos dois aos cinco anos, Perroni (1992) já havia constatado esse aumento progressivo na complexidade das perguntas, na medida em que diminuía a participação do adulto. Haden, Haine e Fivush (1997) sugerem chamar de espiral colaborativa esse tipo de suporte do adulto que se modifica diante das aquisições da criança.

No contexto da interação mãe-criança em situação de jogo, Matta (2000, citada em Matta, 2004) também verificou que as mães de crianças de três a cinco anos oferecem um suporte para o estabelecimento de relações, planificação, definição de objetivos, papéis e avaliação da situação de jogo. Com as crianças dessa idade, estabelece-se uma parceria mãe-criança e a responsabilidade sobre a tarefa é repartida, cabendo à mãe orientar e interrogar. Já aos 5,6 anos, há uma nítida diminuição das intervenções da mãe.

Essa evolução no tipo de suporte que o adulto oferece à criança na situação de jogo, assim como durante a narrativa de experiências pessoais, parece ser decorrente da transferência que o adulto faz da responsabilidade na realização da tarefa para a criança. Nesse momento, não haveria mais necessidade de transmitir informações e habilidades, uma vez que, aos olhos da mãe, a criança já estaria apta a realizar a tarefa por si mesma, isto é, já teria internalizado e transformado os conhecimentos necessários à realização da tarefa.

No que concerne a como perguntar, Michaels (2002) sugere que as questões devem ir do geral para o particular e estar ritmicamente sincronizadas, isto é, ocorrer após a criança fazer uma pausa com um tom decrescente. As questões, assim, não serão vistas como interrupções, porque essas pausas da criança indicam uma espécie de fechamento. Para a autora, o sentido compartilhado do tópico e a sincronização dos intercâmbios com o adulto tornam a criança capaz de desenvolver melhor o 
seu relato.

No que se refere aos tipos específicos de perguntas que melhor funcionam como suporte para narrar, Low e Durkin (2001) e Peterson e McCabe (1994) observam que quando os pais ou outros adultos perguntam questões específicas sobre quem, o quê, quando, por que e onde, conseqüentemente ampliam as respostas das crianças. Essas perguntas fornecem uma codificação para as histórias, que as encoraja a fazerem conexões entre os eventos.

As mães podem estruturar os eventos passados com seus filhos de diferentes maneiras, e esses estilos maternos têm relação com o desenvolvimento narrativo das crianças (Fivush, 1991; Peterson \& McCabe, 1994 ; Reese, Haden, \& Fivush, 1993). Fivush (1991) distinguiu dois diferentes estilos narrativos exibidos pelas mães. O estilo altamente elaborador, que se verifica em mães que freqüentemente falam sobre o passado com seus filhos, e utilizam uma variedade de estratégias para eliciar um resultado mais elaborado e rico. Essa descrição lembra a das mães que ampliam o tópico no estudo de Peterson e McCabe (1994), que fazem perguntas específicas (onde, quando, quem e o que aconteceu) para obter informações de orientação que situam o contexto espaço-temporal e para esclarecer ações. O estilo pouco elaborador, por sua vez, corresponde às mães que se referem menos ao passado, e que, quando o fazem, perguntam pouco, oferecem descrições mínimas e tendem a fazer comentários repetitivos. Contudo, Reese, Haden e Fivush (1993) explicitam que o fator determinante não é a quantidade de informações que a mãe fornece, mas a maneira como a forma narrativa é ensinada. Assim, as mães que desde cedo fornecem narrativas densas, temporal e informacionalmente complexas, têm crianças que produzem narrativas igualmente densas mais tarde. Mães que fornecem mais informações de orientação e avaliação em suas conversas sobre o passado têm crianças que incluem mais esse tipo de informação em suas narrativas pessoais subseqüentes. Fivush (1991) chama a atenção para a bidirecionalidade desse procedimento, uma vez que a habilidade verbal da criança pode influenciar o estilo narrativo da mãe, já que a criança que é verbalmente mais sofisticada elicia um estilo narrativo mais sofisticado em sua mãe. Reese e Fivush (1993) constataram que os pais podem apresentar aspectos dos dois estilos e diferirem no grau em que demonstram cada um, e que os pais de meninas tendem a ser mais elaboradores do que os pais de meninos.

Ainda sobre a influência da maneira como as mães estruturam os eventos passados com seus filhos, Nelson (1998) observou que algumas mães enfatizam mais os aspectos subjetivos, afetivos e relacionais da experiência, enquanto outras privilegiam a objetividade dos fatos. Ao enfatizar aspectos subjetivos da experiência, as mães incentivam os filhos a buscarem a coerência da história, enquanto que, ao enfatizarem a objetividade, fornecem a seus filhos uma estrutura mais imbricada com a seqüência dos fatos no tempo.

Finalmente, observam-se diferenças culturais no estilo materno de participar em interações verbais com crianças. Melzi (2000), em uma pesquisa com mães estadunidenses de origem latina e de origem européia, verificou que as mães de origem latina estão mais interessadas em desenvolver a habilidade da criança para participar em uma conversação, enquanto as mães de origem européia procuram desenvolver a habilidade da criança de contar uma história organizada. Essas variações refletem as diferenças quanto aos objetivos de socialização e padrões conversacionais de cada cultura.

\section{Das narrativas conjuntas à autoria da própria história de vida}

Bruner (1986/1997a, 1991) definiu narrativa como uma forma convencional, transmitida culturalmente, que trata das intenções humanas e, mais tarde, como um instrumento mental e discursivo de construção da realidade. As convenções narrativas são padrões aos quais as histórias devem ajustar-se, a fim de serem reconhecidas em uma cultura. $\mathrm{O}$ autor acredita que existe uma predisposição para organizar as experiências em forma narrativa, e que não há outra maneira de descrever o tempo vivido (1987, 1990/1997b). Reforçando esse argumento, Brockmeier e Harré (2003) explicam que a forma narrativa permite conceber a realidade em constante transformação e que possibilita dar ordem e coerência à experiência e fazer alterações, quando a experiência, ou seu significado, transforma-se. Assim, é possível conversar sobre o passado e o futuro, e a própria vida se torna compreensível, devido aos sistemas culturais de interpretação, codificados em forma narrativa (Bruner, 1986/1997a). Esta permite compreender como as experiências e atos das pessoas são moldados por suas intenções (Bruner, 1990/1997b). Então, a construção de histórias em forma narrativa ajuda a pessoa a compreender a si mesma e aos outros, porque possibilita inferir sobre suas mentes.

Falar sobre o passado com histórias sobre nós, para nós mesmos e para os outros tem um importante papel em nossa vida, pois participa na construção de nosso autoconceito. Habermas e Paha (2001) acrescentam que conceber a si mesmo através de uma perspectiva biográfica coerente, contribui ativamente para constituir o que fomos, somos e seremos. Desse modo, as narrativas participam da constituição dos modelos de mundo e de self, como mediadoras entre o indivíduo e a cultura. Nelson (2000) argumenta que o self emerge como resultado das trocas verbais com outros significativos desde a tenra infância, através da forma narrativa a respeito de experiências compartilhadas ou não, e das histórias e mitos que alicerçam a cultura. Para a autora, essas trocas com os outros fornecem ao self a noção de continuidade no tempo, desde um nascimento que não é possível lembrar indo para além do momento de vida da pessoa, para um ponto imaginado da fase adulta ou da velhice. Parece, portanto, existir um consenso de que grande parte do que somos depende do que pensamos de nosso passado, e alguns autores propõem que a narrativa de histórias de vida representa um esquema avaliativo para interpretar o passado (Fivush, 1991; Nelson, 1998).

Pesquisas indicam que a maneira como os adultos falam de eventos ocorridos no passado com as crianças quando pequenas influencia a maneira como elas irão lembrar e compreender esses eventos (Fivush, 1991; Fivush \& Haden, 1997; Peterson \& McCabe, 1991; Reese \& Fivush, 1993). Welch-Ross (1997) explica que durante as conversas sobre experiências vividas, a criança coordena a própria representação do evento com a de seu parceiro adulto, e participa, assim, de um ato de intersubjetividade 
e atenção compartilhada, o que, além de contribuir para o desenvolvimento do processamento e recordação de cada narrativa, pode influenciar o modo como a criança vai pensar seu passado e sobre si mesma. Reese e Fivush (1993) acrescentam que essas construções conjuntas não servem somente para ajudar a criança a estruturar narrativas autobiográficas, mas também auxiliam a manter as ligações interpessoais através da construção de uma história compartilhada.

Peterson e Biggs (1998) referem que as histórias do que vivemos tornam-se mais coerentes ao serem recontadas, ainda que isso se faça muito espaçadamente no tempo. Bruner(1987) já havia sugerido que devemos olhar as histórias de vida como uma contínua interpretação e reinterpretação de nossa experiência.

\section{A experiência e a forma narrativa}

As relações entre a experiência real e a forma narrativa são discutidas por diversos autores (Bruner, 1990/1997b; Fivush \& Haden, 1997; Nelson, 1998). Fivush e Haden (1997) destacam três posições: os que argumentam que o ato de narrar a experiência cria a relação entre os eventos que vêm antes e, portanto, o significado; os que entendem que as narrativas não criam significado, apenas servem para expressá-lo; e a posição intermediária de Ricoeur (1991), para quem a habilidade para construir narrativas sobre as experiências acrescenta elementos básicos para a compreensão da experiência, de um modo que seria impossível sem a linguagem. Esta posição conduz novamente a Vygotsky, para quem é a linguagem que permite novas formas de pensamento (Penuel \& Wetsch, 1995).

Fivush e Haden (1997) argumentam que as narrativas parecem acrescentar regras para a compreensão dos eventos, para além do que foi disponibilizado diretamente pela experiência. Para sustentar essa afirmação, as autoras indicam que as narrativas fornecem: (a) relações entre os eventos, por meio de informações explícitas de orientação; (b) conexões temporais e causais/condicionais entre os componentes das ações, por meio de marcadores lingüísticos explícitos; (c) causalidade psicológica, por meio de referência explícita a estados internos, motivações, crenças e reações emocionais e, por fim; (d) o significado individual e o sentido que o evento tem para a pessoa, pelo uso explícito de avaliações. As autoras justificam, assim, porque as narrativas transmitem coerência e significado aos eventos vividos por meio da linguagem.

Em pesquisa recente, McGuigan e Salomon (2004) constataram que falar depois de um evento beneficia potencialmente a recordação do mesmo, pois fornece uma oportunidade para codificar a localização espacial, permite que a criança dê sua contribuição para a conversação e pratique a tarefa de relembrar, que será exigida em futuras conversas sobre o mesmo tópico. Indo mais além, Matta (2004), num estudo ambientado num primeiro momento no Oceanário de Lisboa, dividiu crianças de cinco a sete anos em três grupos: o primeiro grupo recebeu informações em forma narrativa, o segundo em forma descritiva e o terceiro não recebeu qualquer informação. Passados 15 dias, as crianças dos três grupos foram entrevistadas e os resultados mostraram que o grupo que recebeu informações em forma narrativa produziu mais informações, em relatos com maior organização e complexidade, enquanto aquele que não recebeu informações reteve significativamente menos.

No Brasil, há um interesse crescente no tema das narrativas infantis, sobretudo na área da lingüística (Guimarães, 1999; Melo 2005, 2006; Motta, Enumo, Rodrigues, \& Leite, 2006) e do desenvolvimento narrativo, integrando a cognição e a produção de narrativas oral e escrita (Silva \& Spinillo, 2000; Spinillo, 1993). Nesses estudos, o procedimento mais utilizado é pedir que a criança descreva figuras, reconte histórias (de livros ou da tradição oral) ou crie histórias a partir dos estímulos apresentados. Outros estudos investigam narrativas para apreender a realidade de crianças vivendo em situação de pobreza (Sawaya, 2001), ou para sondar o imaginário das crianças, por exemplo, na Amazônia (Alves, 2006). Contudo, são raros os estudos brasileiros que investigam como a criança aprende a organizar suas experiências pessoais em narrativas. E ainda mais raros são estudos cujo foco seja a interação verbal mãe-criança durante o relato de experiências pessoais.

As narrativas sobre experiências pessoais se constituem como o primeiro gênero de narrativa a se desenvolver, e iniciase entre 24 e 36 meses (Peterson \& McCabe, 1991). A mesma criança pode demonstrar níveis diferentes de habilidade para narrar se comparadas narrativas de experiências pessoais, narrativas ficcionais e reconto de histórias (Shiro, 2003).

\section{O desenvolvimento da habilidade para narrar uma experiência vivida}

As narrativas infantis construídas para recuperar lingüisticamente uma seqüência de experiências efetivamente vividas pelo narrador, muitas vezes compartilhadas com a mãe, necessitam coerência e um certo compromisso com a verdade. A esse respeito, McCabe e Peterson (1991) acrescentam que as experiências compartilhadas conduzem a um suporte verbal materno mais ativo, enquanto que as não compartilhadas permitem que a criança tenha melhor desempenho.

No que concerne ao domínio das convenções e da estrutura própria das histórias infantis, as narrativas orais apresentam uma evolução que depende da idade e da escolaridade (Shapiro \& Hudson,1991; Silva \& Spinillo, 2000; Spinillo, 1993), sendo o efeito da escolaridade considerado mais marcante (Spinillo, 1993). Além disso, vários autores verificaram que as crianças precisam captar o significado de uma seqüência inteira de eventos para estruturar seus discursos e, assim, contar uma história coerente (Shapiro \& Hudson, 1991; White \& Low, 2002).

Com relação à idade, Perroni (1992) observou que a partir dos quatro anos a criança passa a tomar a iniciativa de relatar eventos/ações passados, independentemente da eliciação do adulto, o que significa um passo importante para a sua constituição como narrador. Ao redor dos cinco anos, a autora observou que o papel do adulto nas situações de discurso narrativo com a criança passa a ser menos ativo. Além disso, observou que a criança dessa idade não narra quando o adulto lhe cobra uma narrativa. Hudson e Shapiro (1991) também observaram que quando a criança é capaz de fazer sozinha uma narrativa de experiência pessoal, ela fica livre para enfocar os aspectos realmente importantes das experiências, segundo sua própria perspectiva, e não amarrada a perguntas que seguem a perspectiva do adulto sobre os eventos. 
Quanto à habilidade para organizar os eventos em uma seqüência, Peterson e McCabe (1983) verificaram que alguns padrões sucedem-se durante o desenvolvimento da criança. Ao analisarem 1124 narrativas de 96 crianças, observaram dois padrões típicos de crianças pequenas: o padrão cronológico, que consiste na simples descrição de eventos que se sucedem; e o padrão "pulo de sapo", em que a narrativa pula de um evento para outro, e deixa de lado fatos importantes que devem ser inferidos pelo ouvinte. Dos quatro aos cinco anos, as crianças evoluem da elaboração de uma lista de ações temporalmente desorganizadas até a elaboração de narrativas que seguem a seqüência temporal dos eventos, mas terminam abruptamente no ponto culminante da história. Já a incidência do padrão clássico de história aumenta com a idade e este padrão é o mais comum aos seis anos. Nessa idade, as crianças orientam seus ouvintes quanto a quem, o quê, onde e quando algo aconteceu, fornecem a complicação da ação, chegando até o clímax do evento e, às vezes, fornecem uma coda, na qual retomam os eventos da narrativa. Outros estudos constataram que crianças de seis anos estão aptas a produzir e lembrar histórias coerentes em scripts baseados em eventos familiares (Hudson \& Nelson, 1983; Low \& Durkin, 1998; 2000).

As crianças adquirem durante seu desenvolvimento uma maior flexibilidade e habilidade para descrever histórias de seqüências inesperadas, quer dizer, histórias mais independentes do canônico (Hudson \& Nelson, 1983; Low \& Durkin, 1998, 2000). Entretanto, Fivush e Haden (1997) advertem que, embora uma criança mais jovem possa construir tão bem quanto uma criança mais velha seqüências com figuras de eventos familiares, sua habilidade para seqüenciar não é flexível. Por exemplo, as crianças mais velhas podem seqüenciar tanto eventos familiares, quanto não-familiares, de trás para frente e de frente para trás. Porém, é somente após os oito anos que a produção e a recordação de histórias começam a obedecer a estrutura gramatical da história, incluindo objetivos, obstáculos a vencer e reações internas.

No que concerne à composição da narrativa, algumas pesquisas constataram que as histórias de pré-escolares freqüentemente enfocam os componentes básicos da narrativa, como as ações e os diálogos (Botvin \& Sutton-Smith, 1977; Van den Broeck, Lorch, \& Thurlow., 1996). Umiker-Sebeok (1979) observou que as crianças pequenas tendem a incluir mais informações sobre o contexto e as ações do evento do que fazer avaliações. E com o passar do tempo, as crianças passam a incluir mais informações de orientação, com mais detalhes e de forma mais sofisticada. Também foi constatado que as avaliações de crianças de quatro anos referem-se predominantemente a reações emocionais, enquanto que aos cinco anos, além das reações emocionais, são usados marcadores de intensidade e quantidade, junto a comparações. Peterson e Biggs (1998) observaram que, quando se trata de eventos estressantes, em qualquer idade as crianças produzem narrativas menos coerentes, contendo menos informações de avaliação, do que quando narram eventos nãoestressantes. Contudo, a interferência das reações emocionais vinculadas ao evento a ser narrado produz efeitos diferentes de acordo com a idade. Segundo as autoras, as narrativas de eventos estressantes das crianças mais velhas (9-13 anos) eram menos coerentes quanto maior a intensidade das emoções e incluíam mais orientações espaço-temporais. Já as narrativas de eventos estressantes de crianças menores (dois a três anos) continham menos orientações espaço-temporais.

É preciso ainda considerar que existem diferenças culturais que influenciam quais conteúdos relativos às experiências pessoais serão lembrados, e como. Han, Leichtman e Wang (1998) encontraram diferenças de conteúdo nas memórias de experiências pessoais de crianças de quatro e seis anos, de origens americana e asiática. Os resultados mostraram que as crianças americanas fornecem mais informações sobre eventos passados específicos, são mais descritivas, fazem mais referências a estados internos (e.g., avaliações) e mencionam mais a si mesmas do que os outros. Wang, Leichtman e Davies (2000) constataram que o ambiente sociolingüístico da criança dá forma e contribui para as diferenças culturais referentes ao conteúdo das memórias precoces da infância.

No que se refere ao número médio de sentenças por narrativa, esperado para crianças que têm entre quatro e cinco anos, há uma discrepância entre os dados dos diferentes estudos relatados na literatura. A média de sentenças por narrativa encontrada por Peterson e McCabe (1983) para crianças de cinco anos é de 7,3 para meninas e de 8,1 para meninos. Contudo, as crianças de 40 meses do estudo de Fivush e Haden (1997) obtiveram uma média de 10 sentenças por narrativa. A diferença entre as classes sociais a que pertencem as crianças dessas duas amostras talvez possa explicar essa discrepância.

Num estudo brasileiro recente, Macedo (2006) solicitou a seis mães que gravassem em casa as conversas sobre experiências pessoais de seus filhos de quatro a cinco anos. Cada díade gravou uma hora de conversação, ao longo de um período de dois meses. As crianças produziram de três a dez narrativas de experiências pessoais, num total de 37 narrativas. A média de sentenças por narrativa para as meninas foi de 18,3; com uma variação de 10,6 e 22,5 sentenças. Já para os meninos, a média de sentenças por narrativa foi de 13,2; com uma variação de 8,8 e 16,4. O resultado desse estudo se aproxima dos resultados de Fivush e Haden (1997), que também utilizaram uma amostra de crianças provenientes da classe média. Os resultados de Haden, Haine e Fivush (1997), como os desse estudo, também mostraram que as narrativas de meninas eram mais longas.

O estudo de Macedo (2006) encontrou diferenças nos tipos de avaliações de meninos e meninas. As meninas se referem mais a estados internos, o que inclui seus sentimentos, idéias e funções mentais (por exemplo, "estou pensando" ou "lembrando"). Essa diferença de gênero foi encontrada também por Fivush e Haden (1997). As meninas também utilizaram mais marcadores de intensidade e quantidade junto com comparações $(10,5 \%$ das avaliações de meninas e 4,7\% das de meninos). Esse tipo de avaliação é esperado em crianças de cinco anos, segundo Umiker-Sebeok (1979). Além disso, apenas as meninas fizeram avaliações considerando coisas que poderiam ter acontecido. Já os meninos desse estudo, interpretaram mais do que as meninas o que pensam e sentem os outros (38\% das avaliações de meninos e $10,5 \%$ das de meninas).

Esses resultados provêm de uma amostra pequena, que foi investigada durante um curto espaço de tempo; no entanto, 
produzem indagações. Como lembram Valsiner e Benigni (1986), a criança se desenvolve dentro de um contexto de significados da cultura que fornece aos pais os esquemas para a compreensão das metas e métodos de educação. É possível pensar que essas diferenças encontradas na forma de avaliar a experiência vivida podem refletir os padrões culturais para a educação de meninos e meninas. Assim, pode ser que o padrão para a educação de meninos ainda seja desenvolver as habilidades necessárias para ataque e fuga. Em contrapartida, as meninas seguiriam sendo mais preparadas para voltarem o olhar para o que acontece dentro de si mesmas e, portanto, estimuladas a pensar mais nos riscos.

\section{Considerações finais}

O objetivo deste artigo foi revisar as contribuições da psicologia ao estudo do desenvolvimento da habilidade da criança para narrar experiências pessoais. É possível dizer que nessa última década ocorreu uma produção interessante de pesquisas brasileiras sobre narrativas de crianças, com destaque para a área da psicolingüística e da psicologia cognitiva, examinando as inter-relações entre cognição e linguagem no desenvolvimento da produção oral e escrita de narrativas. Há ainda uma utilização das narrativas de crianças como um meio de acessar sentimentos e dinâmica interna (Sawaya, 2001).

A busca realizada nos meios disponíveis indica algumas tendências nos estudos sobre narrativas no Brasil. Revelam, por exemplo, que os psicólogos brasileiros que estão interessados numa perspectiva desenvolvimental têm optado pelo procedimento de solicitar que a criança crie ou reconte histórias a partir de livros, figuras, filmes ou outros estímulos prontos, e raramente investigam experiências pessoais. Além disso, quando o foco das pesquisas são as interações narrativas de adultos com crianças pequenas, estas têm sido estudadas predominantemente no contexto escolar e envolvem interações com professores ou com o próprio pesquisador, como em Melo (2005, 2006), Miranda (2000) e Smith (2006). Em outras culturas, esta tendência também existe, por exemplo, Matta (2004) em Portugal e Rosemberg e Manrique (2007) no Chile. Especificamente quanto ao estudo de narrativas de experiências pessoais na interação mãe-criança, os trabalhos de Perroni (1992) e Macedo (2006), no Brasil, e até onde foi possível verificar, ainda se constituem como exceção.

Já com relação à literatura internacional recente, o estudo das narrativas de experiências pessoais tem seguido dois caminhos: um deles permanece sendo o exame do desenvolvimento narrativo na interação mãe-criança (Becker, 2005; Peterson \& Roberts, 2003). O segundo caminho escolhido pelos autores de língua inglesa, sob influência do trabalho de Katherine Nelson (Bauer, Fivush, Hudson, \& Lucarielo, 2004), implica numa ampliação de foco, incorporando ao estudo das narrativas de experiências pessoais, o desenvolvimento da memória autobiográfica e do self(Fivush \& Haden, 2003) e as diferenças de gênero e culturais nesses desenvolvimentos (Fivush \& Nelson, 2004). Este parece ser um interessante desdobramento dos estudos sobre o desenvolvimento das narrativas de experiências pessoais de crianças.
O estudo das narrativas de experiências pessoais em crianças traz contribuições importantes para a área do desenvolvimento lingüístico e cognitivo, especialmente no que se refere à memória. Além dessas contribuições, é importante estudar esse tema porque a forma narrativa serve de instrumento de ligação entre o passado, presente e futuro, possibilitando assim, a construção da história e da identidade da família e de cada um de seus membros. Nesse sentido, a forma narrativa permite ao pensamento transitar através do tempo e do espaço, organizar a história de uma vida e marcar o pertencimento do sujeito a uma determinada família e cultura. A ação de compartilhar uma experiência permite que a história de quem conta se entrelace à história de quem ouve. Entre pessoas da mesma família, esse compartilhar leva, ainda, à intimidade e proximidade, o que conduz ao sentimento de amar e se sentir amado.

\section{Referências}

Alves, L. M. (2006). Constituição do discurso narrativo polifônico da criança em Bathkin: um estudo dos contos de fadas e das lendas da Amazônia. Tese de doutorado não-publicada, Pontifícia Universidade Católica de São Paulo, São Paulo.

Bauer, P., Fivush, R., Hudson, J., \& Lucarielo, J. (2004). Kaherine Nelson's vision of mediated mind. In J. Lucarielo, J. Hudson, R. Fivush, \& P. Bauer (Orgs.), The development of mediated mind (pp. 1-11). Mahwah, New Jersey: Lawrence Erlbaum.

Becker, T. (2005). The role of narrative interaction in narrative development. In U. M. Quasthoff \& T. Becker (Orgs.), Narrative interaction (pp. 93-112). Amsterdam \& Philadelphia: John Benjamins.

Botvin, G., \& Sutton-Smith, B. (1977). The development of complexity in children's fantasy narratives. Developmental Psychology, 13, 377-388.

Brockmeier, J., \& Harré, R. (2003). Narrativa: problemas e promessas de um paradigma alternativo. Psicologia Reflexão e Crítica, 16(3), 525-535.

Bruner, J. (1987). Life as narrative. Social Research, 54(1), 11-32.

Bruner, J. (1991). The narrative construction of reality. Critical Inquiry, 18, $1-21$.

Bruner, J. (1997a). Realidade mental mundos possiveis (M. A. G. Domingues, Trad.). Porto Alegre: Artes Médicas. (Texto original publicado em 1986)

Bruner, J. (1997b). Atos de significação (S. Costa, Trad.). Porto Alegre: Artes Médicas. (Texto original publicado em 1990)

Costa, E. V., \& Lyra, M. D. P. (2002). Como a mente se torna social para Barbara Rogoff? A questão da centralidade do sujeito. Psicologia Reflexão e Crítica, 15(3), 637-647.

Dunn, J. (1988). The beginnings of social understanding. Cambridge, Massachusetts: Harvard University Press.

Fivush, R. (1991). The social construction of personal narratives. Merrill-Palmer Quartely, 37(1), 59-82.

Fivush, R., \& Haden, C. A. (1997). Narrating and representing experience: preschoolers' developing autobiographical accounts. In P. W. Van den Broek, P. J. Bauer, \& T. Bourg (Orgs.), Developmental spans in event comprehension and representation (pp. 169-196). Mahwah, New Jersey: Lawrence Erlbaum.

Fivush, R., \& Haden, C. (2003). Introduction: autobiographical memory, narrative and self. In R. Fivush \& C. Haden (Orgs.), Autobiographical memory and the construction of a narrative self ( $\mathrm{pp}$. vii-xiv). Mahwah, New Jersey: Lawrence Erlbaum.

Fivush, R., \& Nelson, K. (2004). Culture and language in the emergence of autobiographical memory. Psychological Science, 15(9), 573-577.

Guimarães, A. M. (1999). Desenvolvimento de narrativas: introdução de referentes no universo textual. Linguagem \& Ensino, 2(2), 91-108.

Habermas, T., \& Paha, C. (2001). The development of coherence in adolescents' 
life narratives. Narrative Inquiry, 11(1), 35-54.

Haden, C. A., Haine, R. A., \& Fivush, R. (1997). Developing narrative structure in parent-child reminiscing across the preschool years. Developmental Psychology, 33(2), 295-307.

Han, J., Leichtman, M., \& Wang, Q. (1998). Autobiographical memory in Korean, Chinese and American children. Developmental Psychology, 34(4), 701-713.

Hudson, J., \& Nelson, K. (1983). Effects of script structure on children's story recall. Developmental Psychology, 19(4), 625-635.

Hudson, J. A., \& Shapiro, L. S. (1991). From knowing to telling: the development of children's scripts, stories and personal narratives. In A. McCabe \& C. Peterson (Orgs.), Developing narrative structure (pp. 89-136). Mahwah, New Jersey: Lawrence Erlbaum.

Low, J., \& Durkin, K. (1998). Structure and causal connections in children's on-line television narratives: what develops? Cognitive Development, 13, 201-225.

Low, J., \& Durkin, K. (2000). Event knowledge and children's recall of television based narratives. British Journal of Developmental Psychology, 18, $247-$ 267.

Low, J., \& Durkin, K. (2001). Individual differences and consistency in maternal talk style during joint story encoding and retrospection: associations with children's long-term recall. International Journal of Behavioral Development, 25(1), 27-36.

Macedo, L. S. R. (2006). Conversar sobre o passado na interação mãe-criança. Dissertação de mestrado não-publicada, Universidade Federal do Rio Grande do Sul, Porto Alegre.

Matta, I. (2004). Aprender vivendo: as experiências de vida no desenvolvimento e na aprendizagem. Análise Psicológica, 1(XXII), 73-80.

McCabe, A., \& Peterson, C. (1991). Getting the story: a longitudinal study of parental styles of narrative elicitation. In A. McCabe \& C. Peterson (Orgs.), Developing narrative structure (pp. 217- 253). Mahwah, New Jersey: Lawrence Erlbaum.

McGuigan, F., \& Salomon, K. (2004). The time to talk: the influence of the timing of adult-child talk on children's event memory. Child Development, $75(3), 669-686$.

Melo, L. E. (2005). Linguagem e cognição: a explicação na criança. Estudos Lingüísticos, XXIV, 809-814.

Melo, L. E. (2006). Competências pragmáticas e lingüísticas na criança: relato de uma experiência. Estudos Lingüísticos, $X X X V$, 1107-1112.

Melzi, G. (2000). Cultural variations in the construction of personal narratives: Central American and European American mothers' elicitation styles. Discourse Processes, 30(2), 153-177.

Michaels, S. (2002). Apresentação de narrativas: uma preparação oral para a alfabetização com alunos da primeira série. In J. Cook-Gumperz (Org.), A construção social da alfabetização (pp. 109-137). Porto Alegre: Artes Médicas.

Miranda, S. L. (2000). Adulto e criança construindo histórias conjuntamente: formas de assistência. Revista SymposiuM, 4, número especial, 50-59.

Motta, A. B., Enumo, S. R. F., Rodrigues, M. M. P., \& Leite, L. (2006). Contar histórias: uma proposta de avaliação assistida da narrativa infantil. Interação em Psicologia, 10(1), 157-167.

Nelson, K. (1998). Commentary on Mark Freeman's "Mythical Time, Historical Time, and the Narrative Fabric of Self". Narrative Inquiry, 8(2), 409-418.

Nelson, K. (2000). Narrative, time and emergence of the encultured self. Culture \& Psychology, 6(2), 183-196.

Penuel, W. R., \& Wertsch, J. V. (1995). Vygotsky and identity formation: a sociocultural approach. Educational Psychologist, 30(2), 83-92.

Perroni, M. C. (1992). O desenvolvimento do discurso narrativo. São Paulo: Martins Fontes.

Peterson, C., \& Biggs, M. (1998). Stitches and casts: emotionality and narrative coherence. Narrative Inquiry, 8(1), 51-76

Peterson, C., \& McCabe, A. (1983). Developmental psycholinguistics. Nova York: Plenum.

Peterson, C., \& McCabe, A. (1991). Getting the story: a longitudinal study of parental styles in eliciting narratives and developing narrative skill. In A. McCabe \& C. Peterson (Orgs.), Developing narrative structure (pp. 215253). Mahwah, New Jersey: Lawrence Erlbaum.

Peterson, C., \& McCabe, A. (1994). A social interacionist account of developing decontextualized narrative skill. Developmental Psychology, 30(6), 937948.

Peterson, C., \& Roberts, C. (2003). Like mother, like daughter: similarities in narrative style. Developmental Psychology, 39(3), 551-562.

Reese, E., \& Fivush, R. (1993). Parental styles of talking about the past. Developmental Psychology, 29(3), 596-606.

Reese, E., Haden, C., \& Fivush, R. (1993). Mother-child conversations about the past: relationships of style and memory over time. Cognitive Development, $8,403-430$.

Ricoeur, P. (1991). O si-mesmo como um outro. Campinas: Papirus.

Rogoff, B. (1990). Apprenticeship in thinking: cognitive development in social context. Nova York: Oxford University Press.

Rosemberg, C. R., \& Manrique, M. S. (2007). Children telling personal experiences in kindergarten: how do teachers promote children's participation? Psykhe, 16(1), 53-64.

Sawaya, S. M. (2001). A infância na pobreza urbana: linguagem oral e a escrita da história pelas crianças. Psicologia USP, 12(1), 153-178.

Shapiro, L. R., \& Hudson, J. A. (1991). Tell me a make-believe story: coherence and cohesion on young children's picture-elicited narratives. Developmental Psychology, 27(6), 960-974.

Shiro, M. (2003). Genre and evaluation in narrative development. Journal of Child Language, 30, 165-195.

Silva, M. E. L., \& Spinillo, A. G. (2000). A influência de diferentes situações de produção na escrita de histórias. Psicologia Reflexão e Crítica, 13(3), 337-350.

Smith, V. H. (2006). A construção do sujeito narrador: organização do pensamento discursivo e a imaginação. Tese de doutorado não-publicada, Universidade Federal do Rio Grande do Sul, Porto Alegre.

Spinillo, A. G. (1993). Era uma vez... E foram felizes para sempre: esquema narrativo e variações experimentais. Temas de psicologia, 1, 67-87.

Umiker-Sebeok, J. (1979). Preschool children's intraconversational narratives. Journal of Child Language, 6, 91-109.

Valsiner, J. (1991). Building theoretical bridges over a lagoon of everyday events. Human Development, 34, 307-315.

Valsiner, J., \& Benigni, L. (1986). Naturalistic research and ecological thinking in the study of child development. Developmental Review, 6, 203-223.

Van den Broeck, P., Lorch, E., \& Thurlow, R. (1996). Children's and adults' memory for memory for television stories: the role of causal factors, story-grammar categories and hierarchical level. Child Development, 67, 3010-3028.

Vygotsky, L. S. (1989). A formação social da mente. São Paulo: Martins Fontes. (Texto original publicado em 1930)

Wang, Q., Leichtman, M., \& Davies, K. (2000). Sharing memories and telling stories: American and Chinese mothers and their 3-year-olds. Memory, 8(3), 159-177.

Welch-Ross, M. K. (1997). Mother-child participation in conversation about the past: relationships to preschoolers' theory of mind. Developmental Psychology, 33(4), 618-629.

White, S., \& Low, J. (2002). When mothers turn a visual story into a verbal one for their children: previewing helps with the telling, conversing, and remembering. International Journal of Behavioral Development, 26(4), 360-370. 
Lídia Suzana Rocha de Macedo, mestre em psicologia do desenvolvimento pela Universidade Federal do Rio Grande do Sul, é psicóloga clínica, especialista em terapia familiar. Endereço para correspondência: Av. Nilo Peçanha, 2715, Ap. 202 (Chácara das Pedras); Porto Alegre, RS; CEP: 91330-001. Tel.: (51) 3779-2353. Fax: (51) 3308-5473. E-mail: lidiasrmacedo@gmail.com

Tania Mara Sperb, doutora em psicologia do desenvolvimento pela University of London (Reino Unido), é professora no Programa de Pós-graduação em Psicologia da Universidade Federal do Rio Grande do Sul. E-mail: sperbt@terra.com.br 